\title{
Dynamic modeling and chatter analysis of a spindle-workpiece-tailstock system for the turning of flexible parts
}

\author{
Kaibo Lu ${ }^{1 *}$, Yongqiang Wang ${ }^{1}$, Fengshou $\mathrm{Gu}^{2}$, Xinyu Pang ${ }^{1}$, Andrew Ball ${ }^{2}$
}

1. College of Mechanical Engineering, Taiyuan University of Technology, Shanxi 030024, P.R. China

2. School of Computing and Engineering, University of Huddersfield, Huddersfield, HD1 3DH, UK

* Corresponding author. Email: 1vkaibo@tyut.edu.cn; Tel: +86-139-0341-8795

\begin{abstract}
Chatter happens frequently in turning of flexible parts, jeopardizing the dynamic stability of the operation. The chatter stability prediction is dependent on the accurate estimation of the structural parameters of the cutting system. This paper aims to quantify the influence of the support conditions on dynamics of the flexible parts in straight turning. Given the time-varying cutting tool position during machining, first the chatter stability of the cutting system along the cutting path is analyzed, and the critical stiffness expression for chatter onset prediction is deduced. Then, two models of the spindle-workpiece-tailstock system using analytical and numerical methods are constructed and compared. The simulation results showed that increasing the spindle bearing or tailstock support stiffness cannot effectively improve the stiffness distribution and the eigenfrequency of the machined rod, whereas the frequency of the system tends to be increased evidently with the chuck size decreased. In comparison with the experimental results, it has been shown that the model involving the effect of spindle bearing and center support enables to produce more accurate modal parameters estimation and chatter onset location prediction than the simplified model. Besides, the measured displacement signals demonstrate a good mapping relation with the theoretical analysis results. The present study could provide an in-depth understanding of the dynamic behavior of flexible workpieces in turning operations.
\end{abstract}

Keywords: Modeling; Turning; Flexible workpieces; Spindle; Chuck; Chatter stability.

\section{Introduction}

Flexible parts or components which are featured with light weight, compact structure, but low stiffness, are widely used in practical applications. Chatter, as well as flexural deformations, is a major obstacle in machining processes of flexible parts, jeopardizing the dynamic stability and geometric accuracy of the operation. The adverse influence makes the analysis and control 
of chatter a significant activity in machining process improvement [1-4]. Although steady or follower rests can be adopted for tooling, the limitation with such measures is that use of the special designs requires the use of many tool holding surfaces in CNC machining centers [5], thus reducing their adaptability. The challenge of turning flexible parts or components has still been faced by many scholars [6-18].

The regenerative phenomena have been recognized as the most important mechanism in modeling of chatter. It is well-documented that machining chatter is due to the interaction between the metal cutting process and the machine tool structure and thereby the machining system stability is dependent on both structural parameters and machining process parameters. In turning operations the strategy that the workpiece is clamped by a chuck at one end and supported by a tailstock at the other end, is one of the most common work-holding forms on the shop floor. According to the comparative rigidity of the workpiece and the cutting tool, three different chatter models are usually proposed, which consist of the tool compliance model $[19,20]$, the workpiece compliance model [7-12], and the compliant tool-workpiece model [13-18]. In general, machining chatter modeling has been done by means of analytical or numerical methods.

In respect of the analytical modeling of turning chatter, the models can be categorized based on the number of degree of freedom (DOF). Urbikain et al. [7] modeled a lumped mass workpiece held between two centers on a lathe as a single degree of freedom (SDOF) system to study the stability using a collocation method. When the compliance of the cutting tool is also taken into account in modeling, a 2DOF chatter model can be formulated, in which the workpiece and the tool are usually described as an SDOF system respectively [8-10]. The simulation results of the proposed compliant model demonstrated a counterintuitive conclusion that the system stiffness reduction would be beneficial to the cutting stability. Siddhpura et al. [11] reported that this dubious viewpoint was verified by their designed experimentation. Lu et al. [12] proposed an analytical model for predicting chatter onset in straight turning of slender workpieces using a continuous Euler-Bernoulli beam, in which the effect of tool movement has been involved. Overall, it can be seen that the support of the chuck and tailstock was generally idealized or simplified as fixed and joint constraints in the proposed models.

With regard to the numerical modeling for chatter stability analysis, finite element method (FEM) was usually adopted. Wang and Cleghorn [13] introduced a finite-element beam model of a stepped shaft workpiece to perform stability prediction using Nyquist criterion, in which 
the chuck and the tailstock were simulated with rotational and translational springs attached to the ends of the workpiece. References [14-17] analyzed the stability of a turning operation through the finite element analysis, and the flexibility of both the tool and the workpiece was included in the model. But the integrity of the results was without validation by experiments. Stepan et al. [18] investigated the varying dynamic properties of flexible workpieces using FEM and proposed a novel 4D (depth of cut, spindle speed, cutting position, and initial work diameter) stability chart for turning operations. The authors, meanwhile, pointed out that the compliance of the bearing system on dynamics of the machined workpiece could not be neglected, which is consistent with the experimental results in [21].

The detrimental effect of chatter vibrations in machining processes has led to a lot of research aimed at modeling chatter and clarifying its causes. In the previous chatter models, very commonly the constraints of the supports of the chuck or tailstock for the turned parts were modeled as fixed ends or pinned joints. However, this simplistic modeling could probably yield unacceptable errors in dynamic analysis of chatter [3, 18, 21]. The reason is that chatter is due to the interaction of the dynamics of the cutting process and the structural characteristics of the cutting system, so it is quite logical that the supports of the chuck and tailstock as part of the machining system could affect the dynamic characteristics and the stability level of the system. Moreover, it has been verified that the spindle bearings as well as the tool-holder or workholder have a non-negligible effect on the high speed spindle dynamics [22-24]. Thus, a realistic description of these boundary conditions in modeling of the cutting system is essential to an accurate prediction of chatter onset.

To gain an in-depth understanding of the influence of the support conditions on the dynamic performance of flexible workpieces in straight turning, the paper presents phenomenological modeling of the fixture of the spindle/chuck and tailstock in two different ways. Following the location-dependent chatter stability analysis along the cutting path, the dynamic characteristics of a spindle-tailstock supported workpiece system are investigated theoretically and experimentally. After that, comparative results of the two models are discussed. Finally, conclusions of this study are given.

\section{Chatter model and stability analysis}

For simplicity this study is focused on the case of a uniform slender rod part with length $L$ and diameter $D$. The workpiece is clamped by the chuck at one end and simply supported by a live center at the other end on a horizontal turning lathe, as shown in Fig. 1(a). The rod is rotating 
at spindle speed $\Omega$ and the cutting tool moves along the Z-axis with constant feedrate $f$. In this case it is reasonable to assume that the spindle-rod-tailstock part is compliant while the frame of the machine tool and the cutting tool are rigid.

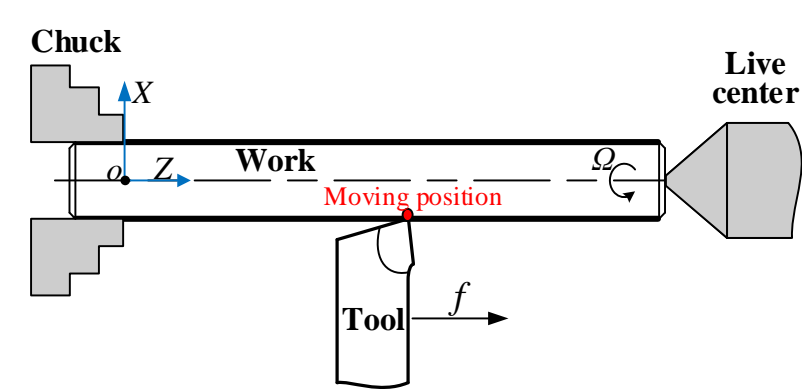

(a)

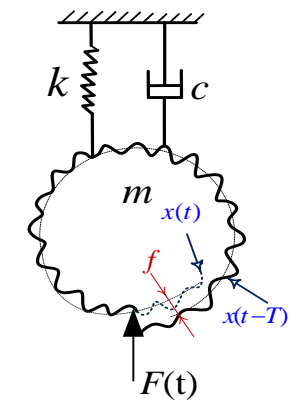

(b)

Fig. 1. Straight turning of a long slender rod: (a) Diagram of cutting system; (b) SDOF chatter model.

Regenerative chatter refers to the cutting force variation due to the dynamic chip thickness produced by regeneration of waviness on both sides of the chip surface. Vibration of the workpiece in the $X$-axis direction is focused on since fluctuations in area of the cut induced by the radial vibration of the workpiece contribute mainly to occurrence of chatter vibrations. Considering that the first mode shape of a dynamic system is usually dominant in the modal participation of mode shapes of vibration, the cutting system can be characterized as an SDOF system, as illustrated in Fig. 1(b). The corresponding equation of motion is a delayed differential equation,

$$
m+k x=K_{c} d f+K_{c} d[x(t-T)-x(t)]
$$

where $m, C$, and $k$ are the equivalent mass, damping coefficient, and stiffness of the system respectively, $K_{c}$ is cutting coefficient related to machining conditions, $d$ is the depth of cut, and $T$ is the time delay.

Technically, the instantaneous cutting force is composed of a static component corresponding to the first term at the right side of Eq. (1) caused by the constant feed motion, and the dynamic component corresponding to the second term caused by the workpiece vibration. The static force may lead to forced vibration of the machined rod, whereas the dynamic one may cause self-excited vibration and thereby determining the cutting stability.

Transforming Eq. (1) into the frequency domain by the Laplace transform and rearranging yields the characteristic equation of the model as follows, 


$$
\frac{1}{Q(s)}+G(s)=0
$$

where $Q(s)=K_{c} d\left(1-e^{-T s}\right)$ is the dynamic stiffness function of the turning operation, and $G(s)=\frac{1}{m s^{2}+c s+k}$ is the receptance transfer function of the lumped-mass workpiece system. This equation formulates the relationship between the cutting process and the structural dynamics of the cutting system for chatter stability analysis. Let $s=j \omega$, the limiting depth of cut for the absolute chatter stability criterion can be formulated according to Tlusty's law $[1,3]$

$$
d_{\lim }=-\frac{1}{2 K_{c} \operatorname{Re}\{G(\omega)\}_{\min }}
$$

where $\operatorname{Re}\{G(\omega)\}$ represents the real part of the transfer function $G(\omega)$. It means that the minimum of $\operatorname{Re}\{G(\omega)\}$ determines the limiting depth or width of cut. Furthermore, the analytical expression of $d_{\text {lim }}$ can be deduced by differentiating $\operatorname{Re}\{G(\omega)\}$ with respect to the chatter frequency $\omega$, which reads

$$
k_{c r}=\frac{K_{c} d_{\lim }}{2 \zeta(1+\zeta)}
$$

where $k_{c r}$ is the critical stiffness of the system corresponding to chatter onset, $\zeta_{w}$ is the damping ratio of the workpiece. According to Eq. (4), it can be inferred that chatter may also emerge when the machining parameters remain the same but the tool moves along the $\mathrm{Z}$ axis of the workpiece. For an adopted depth of cut, if the stiffness of the system is $k \leq k_{c r}$, the cutting appears to be absolutely unstable. On the other hand, for a given cutting position, the stability of a turning operation can be conservatively predicted by the criterion $2 k_{c r} \zeta$ for a known cutting coefficient. And if the depth of cut set in the operation has $d \leq d_{\lim }$, the cutting system will be absolutely stable.

Owing to the tool movement with respect to the workpiece, the structural characteristics of the system will vary with the cutting progressing. Therefore, the equivalent chatter model should be composed of a series of SDOF systems. In the following part, two different modeling methods are explored so as to achieve the dynamic parameters of the spindle-workpiecetailstock cutting system. 


\section{Modeling of the spindle-workpiece-tailstock system}

\subsection{Analytical model}

Similar to studies in literature, the spindle-workpiece-tailstock system here is simplified as a propped cantilever beam model, as shown in Fig. 2. With boundary conditions idealization, for a fixed end the deflection and slope are zero; for a simply supported end the bending moment and deflection are zero [25]. As a result, this model is a statically indeterminate beam.

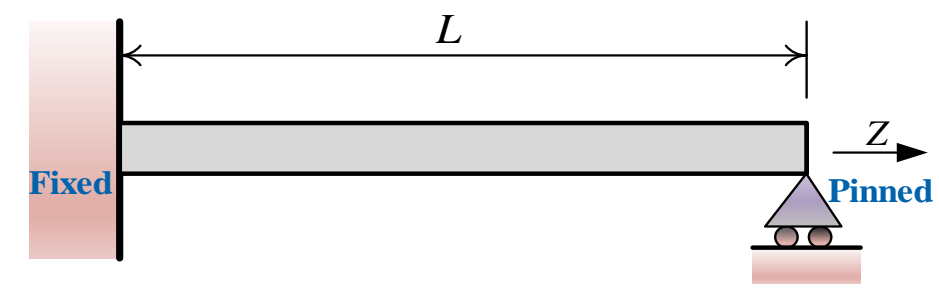

Fig. 2. Simplified model of the spindle-workpiece-tailstock system

According to the knowledge of mechanics of materials, we can deduce the deflection of the beam under a concentrated force $F$ acting at the coordinate $z$ along the workpiece. At the acting point, the deflection of the beam has the form

$$
\delta(z)=\frac{F}{12 E I L^{3}}\left(4 L^{3} z^{3}-9 L^{2} z^{4}+6 L z^{5}-z^{6}\right)
$$

where $E$ is Young's modulus, $I$ is the moment of inertia of the beam cross section. Through dividing both sides of Eq. (5) by the cutting force $F$, the location-dependent flexural stiffness $(F / \delta)$ of the workpiece can be obtained as

$$
k(z)=\frac{12 E I L^{3}}{4 L^{3} z^{3}-9 L^{2} z^{4}+6 L z^{5}-z^{6}}
$$

Moreover, as only the first vibration mode of the workpiece is considered, its fundamental frequency can be calculated using continuous beam theory, which reads

$$
\omega_{n}=3.927^{2} \sqrt{\frac{E I}{\rho A L^{4}}}
$$

where $\rho A$ is the mass per unit length of the workpiece. Finally, the SDOF chatter model with the same natural frequency but varying stiffness is reduced to any cutting point along the length of the workpiece.

3.2 Finite element model 


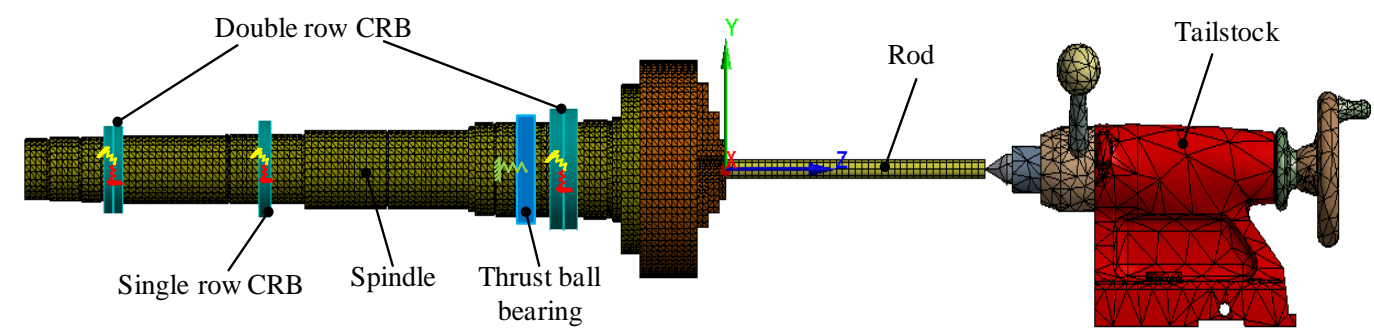

Fig. 3 Finite element model of the spindle-workpiece-tailstock system.

The studied lathe is an industrial Shenyang CA6140 machine tool. Its spindle is supported by three kinds of rolling bearings as shown in Fig. 3, which consist of the double row cylindrical roller bearing $(\mathrm{CRB})$, single row $\mathrm{CRB}$, and thrust ball bearing (one NN3021K double row $\mathrm{CRB}$ at the front, one NN3015K double row CRB at the rear, one NU216 single row at the middle, and two 51120 thrust ball bearings). The hollow spindle has the length $870 \mathrm{~mm}$ and the inner diameter $52 \mathrm{~mm}$. The three-jaw chuck is with the diameter $D_{c}=250 \mathrm{~mm}$ and the thickness 80 $\mathrm{mm}$.

In the FEM of the spindle-workpiece-tailstock system, considering elastic deformations of the rolling bodies and races, as well as deformations of joints between the outer race and the housing and the inner race and the spindle, the bearing stiffness can be estimated via Hertzian contact theory, which has $[5,26]$

$$
k_{b}=\frac{1}{K_{1} / d_{b}+4 / \pi \cdot\left(1+d_{b} / D_{b}\right) \cdot K_{2} /\left(d_{b} b_{b}\right)}
$$

where $d_{b}$ and $D_{b}$ are inner and outer diameters of the bearing, $b_{b}$ is the width of the bearing, $K_{1}$ is $0.66 \times 10^{-10} \mathrm{~m}^{2} / \mathrm{N}$ for narrow roller bearing and $0.44 \times 10^{-10} \mathrm{~m}^{2} / \mathrm{N}$ for wide ones, $K_{2}$ is a coefficient related to precision fits (5 to $25 \times 10^{-11} \mathrm{~m}^{3} / \mathrm{N}$ ). Accordingly, the stiffness of the bearings is obtained as provided in Table 1. For the following calculation, the mean values of the stiffness for each bearing are adopted.

Table 1. Bearing stiffness in the finite element model

\begin{tabular}{|l|l|l|l|l|}
\hline Bearing types & NN3021K & NU216 & NN3015K & 51120 \\
\hline Stiffness $\left(\times 10^{7} \mathrm{~N} / \mathrm{m}\right)$ & $0.82 \sim 4.08$ & $0.42 \sim 2.08$ & $0.43 \sim 2.14$ & $0.45 \sim 2.26$ \\
\hline
\end{tabular}

To simulate the function of the tailstock live center, three spring elements are attached to the front end cross section of the workpiece along $X, Y$, and $Z$ axes, respectively. The spring in the direction $Z$ is used to model the thrust force exerted by the center during the clamping procedure. The stiffness of the springs can be obtained experimentally. In the finite element model, the 
spindle body is meshed in terms of tetrahedral solid elements, while the workpiece is meshed in terms of hexahedral elements using the swept meshing technique. At last, the natural frequency of the model can be calculated through modal analysis; the stiffness of the rod at various positions along its length can be gained using static structural analysis.

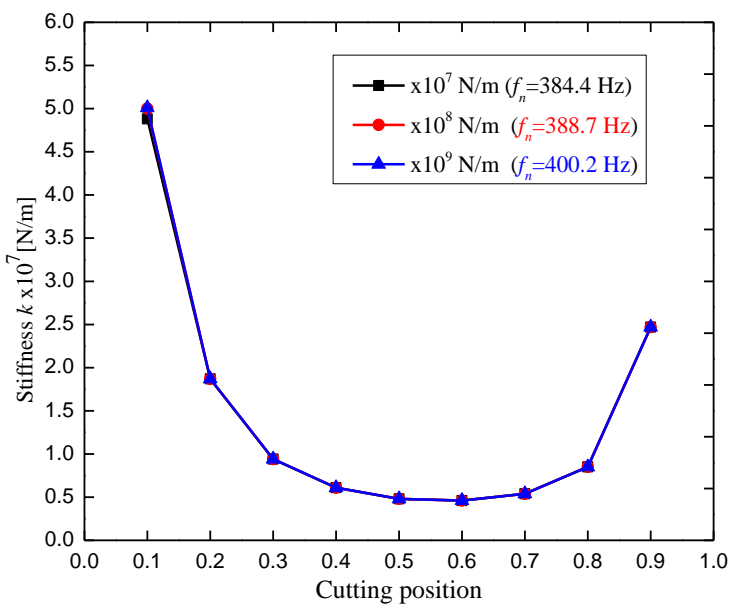

(a)

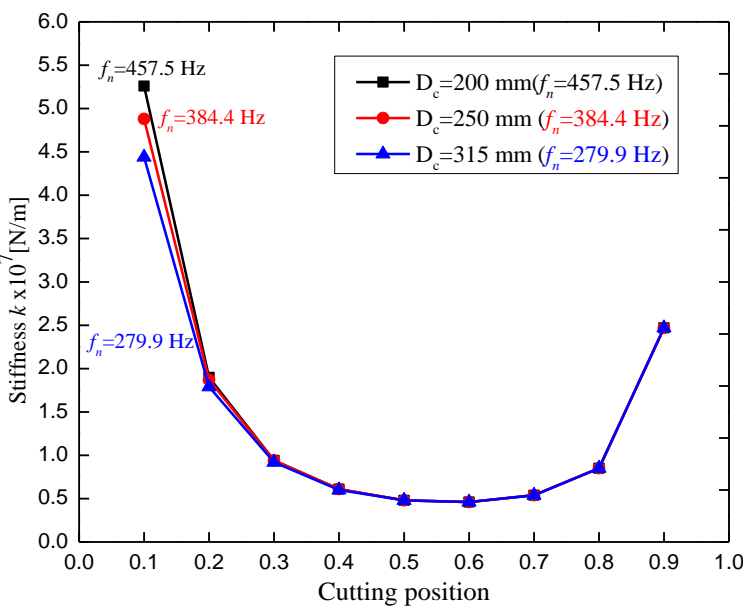

(b)

Fig. 4 Effect of bearing stiffness (a) and chuck size (b) on dynamic characteristics of the turned rod

With the increase of the bearing stiffness, both the stiffness of the workpiece at the positions near the chuck end and the frequency of the system dominated by the bending mode are increased slightly, as seen in Fig 4(a). Note that the cutting position here is expressed in term of the ratio of the distance from the chuck to the total length of the workpiece. The attachment of the spindle, chuck, also has an effect on the dynamic characteristics of the cutting system, as shown in Fig. 4(b). It can be seen that although the size of the chuck has little effect on the stiffness distribution of the machined rod, the natural frequency of the system tends to decrease evidently with the chuck size increasing.

\section{Experimentation and discussion}

This section deals with the comparison of the experimental measurements and the theoretical analysis results. Experiments were performed on a CA6140 conventional horizontal lathe with the power of $7.5 \mathrm{~kW}$. First, static stiffness measurements were conducted. Then, hammer tests were done. Finally, turning trials were performed to observe the dynamic behavior of the flexible rod in operation. The experimental setup is shown in Fig. 5. 

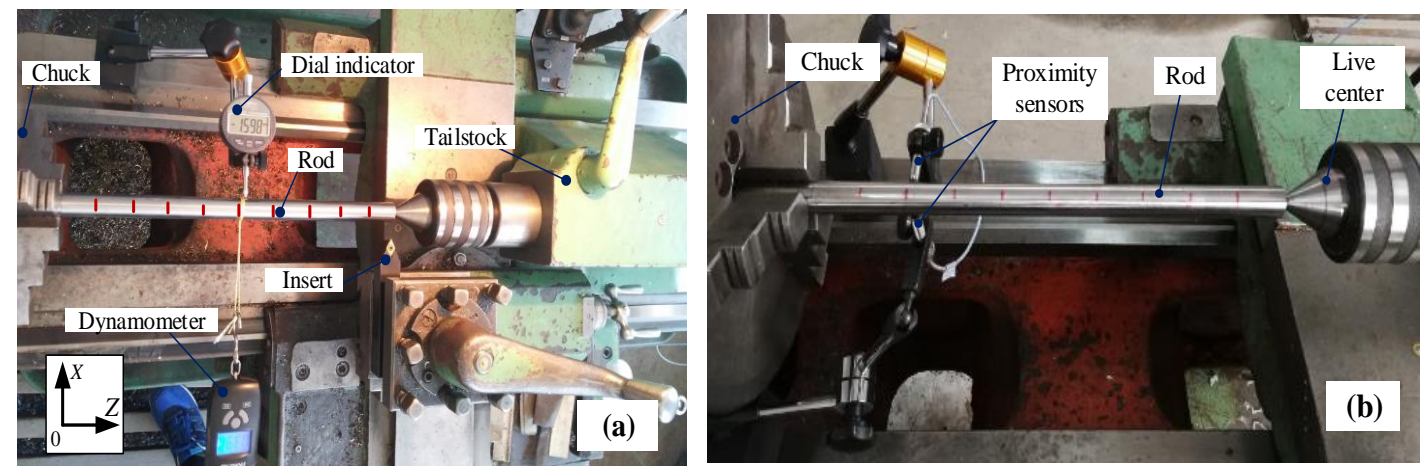

Fig. 5. Experimental setup. (a) Stiffness test; (b) Cutting vibration test.

All the test bars with the length $340 \mathrm{~mm}$ and diameter $22 \mathrm{~mm}$ were made of 1045 steel. The material has the Young's modulus $E=2.06 \times 10^{5} \mathrm{MPa}$ and density $\rho=7850 \mathrm{Kg} / \mathrm{m}^{3}$. The DCMT11T304 carbide insert tool was used. The rhombic insert has nose angle $55^{\circ}$, nose radius $0.4 \mathrm{~mm}$, and clearance angle $7^{\circ}$, respectively. The cutting edge angle remained $62.5^{\circ}$ during machining. An NI data acquisition system was applied to record the measured signals. To reduce the influence of nonlinear factors on the dynamic behavior of the workpiece in machining, apart from coolant implementation to minimize the influence of cutting heat, one fresh tool insert was utilized for each tested rod to eliminate the tool wear effect.

For the static stiffness measurement, firstly a sequence of marks equally spaced along the length of the rod were labeled, as seen in Fig. 5(a). At each mark point, a force meter and a dial indicator were utilized to measure the exerted force and the corresponding deflection. After calculation, the experimental stiffness of the rod with respect to different positions along its axis is achieved, as illustrated in Fig. 6. It can be seen that the experimental values are generally lower than the theoretical results. This mainly attributes to the additional deflection of the intricate jointed parts of the spindle and tailstock [27-29], which, in turn, leads to the decreased stiffness in practice. In comparison with the analytical model, the finite element model enables to produce stiffness closer to the experimental results. Overall, both models could bring about analogous patterns of stiffness distribution along the workpiece, especially at the central part of the rod. By comparison, the location near the chuck side holds higher stiffness than the center side. The lowest rigidity point locates approximately at the coordinate $z=0.6$, implying that chatter vibrations are most likely to happen around this location based on Eq. (4). Following the same procedure, the stiffness of the live center at the tip was measured as $k_{x}=0.74 \times 10^{7}$ $\mathrm{N} / \mathrm{m}$ and $k_{y}=0.84 \times 10^{7} \mathrm{~N} / \mathrm{m}$. 


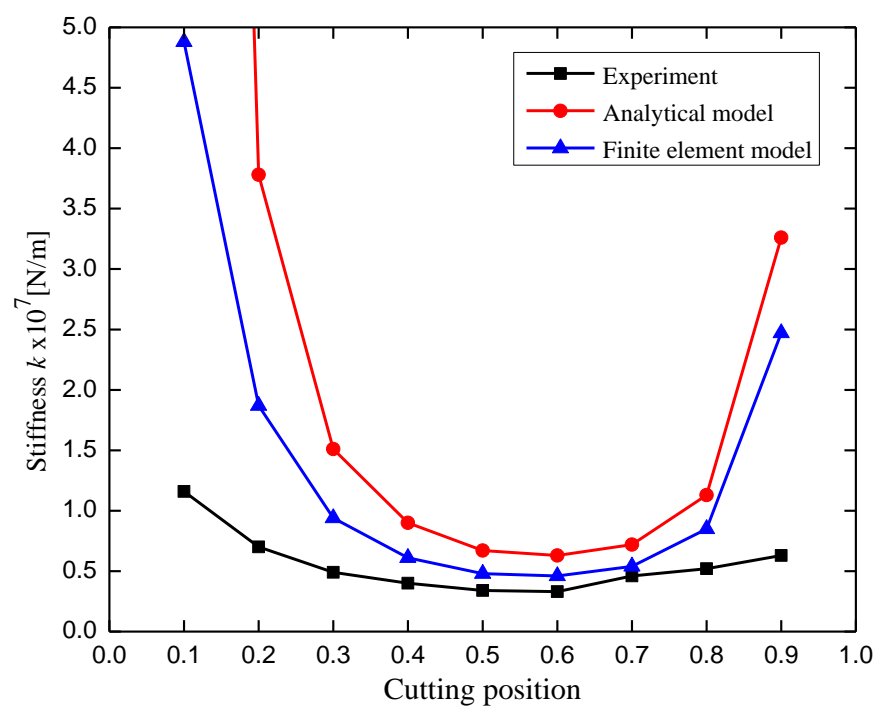

Fig. 6 Comparison of the stiffness distribution along the length of workpiece

For the modal estimation of the spindle-workpiece-tailstock system, hammer tests were carried out. The impact point was at $z=0.3$, and one accelerometer was attached to the rod at the position $z=0.7$ to acquire the response. Through the logarithmic decrement of the measured response, the damping ratio of the system can be calculated as $\zeta=0.043$. Fig.7 illustrates the comparison of the Frequency Response Functions (FRF) of the experimental and proposed models. It is clear that the simplified model has the highest natural frequency, which indicates the analytical model is much stiffer as a result of the ideal assumption of the boundary conditions. The finite model yields the natural frequency close to the measured value, which is consistent with the comparison in Fig. 6.

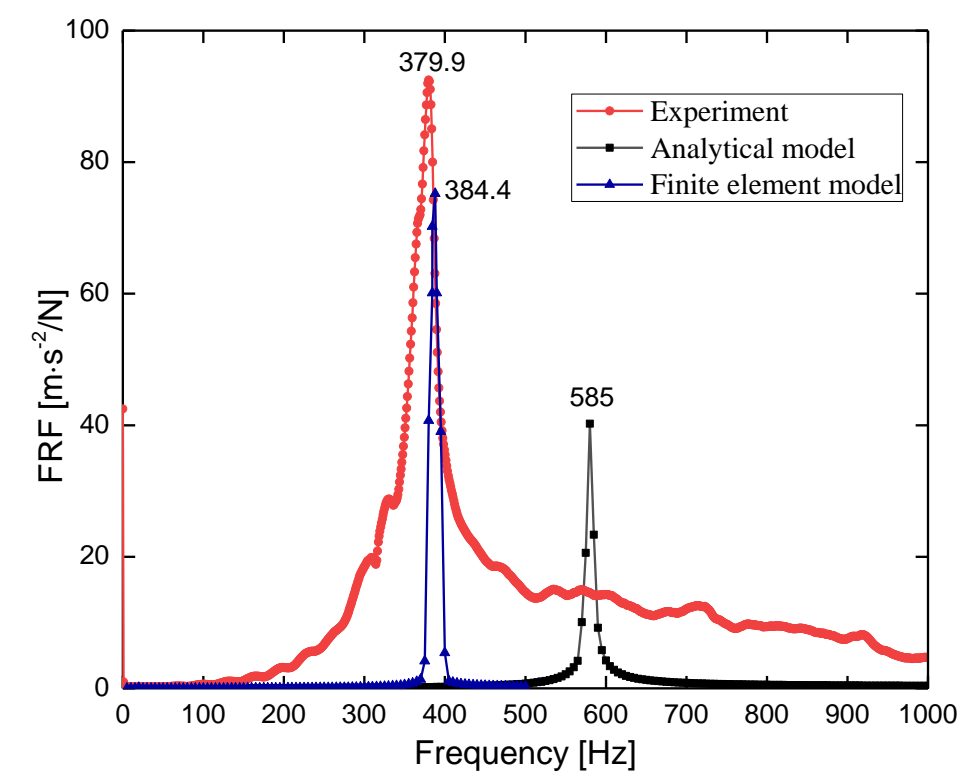

Fig. 7 Comparison of the experimental and theoretical FRFs 
In the machining tests, two proximity sensors were fixed on the slideway to acquire the displacement of the workpiece in $X$ and $Y$ directions respectively, as shown in Fig.5 (b). The sample rate was set to be $2000 \mathrm{~Hz}$. Fig. 8 provides typical vibration signals of the rod in $X$ direction during a straight turning operation, where the machining parameters employed were $d=0.8 \mathrm{~mm}, \Omega=1120 \mathrm{rpm}, f=0.1 \mathrm{~mm} / \mathrm{rev}$, and feed direction is from the tailstock side towards the chuck side. During the machining, it has been observed that the cutting was usually stable initially; but when the tool arrived at the specific positon $z=244.8 \mathrm{~mm}$ along the cutting path chatter vibrations occurred and lasted for a period of time, leaving spiral-shaped marks on the machined surface. This observation resembles the phenomena reported in the previous studies $[12,30,31]$. From Fig. 8, it is noted that the displacement trendline which can be used to estimate the shape error of the machined rod, tends to be descended. This is because of the static cutting force, as formulated in Eq. (1), which gradually pushed the rod towards the proximity probe in $+X$ direction as the tool was moving in $-Z$ direction. This observation corresponds to a decreased zero or DC component but an increased contribution at the spindle rotation frequency in the vibration spectrum, as seen in Fig. 9.

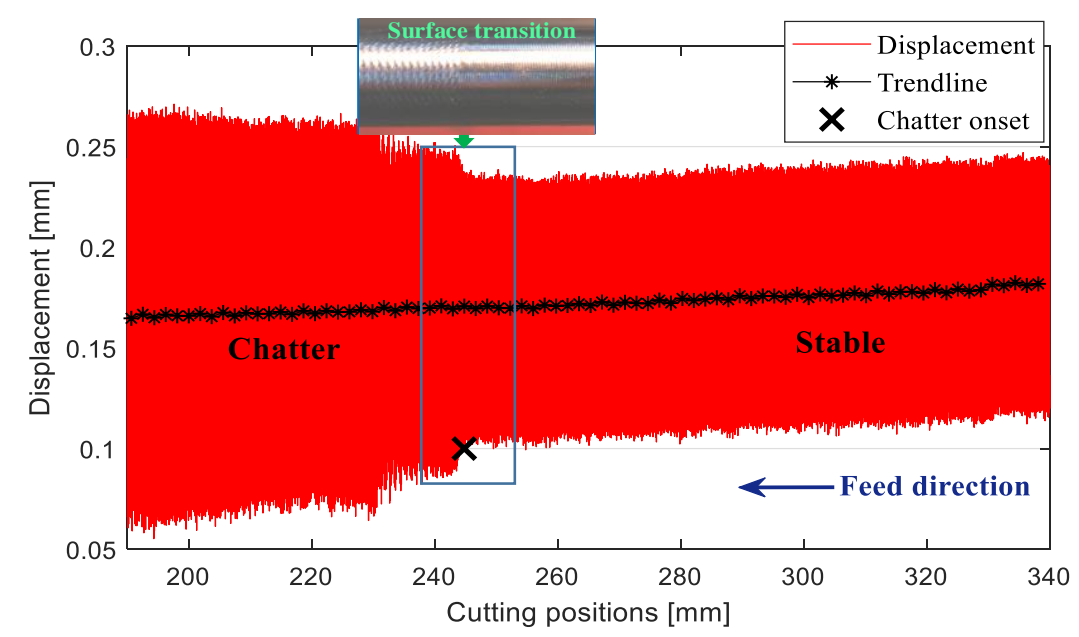

Fig. 8 Displacement signals with respect to different cutting positions during turning

With regard to the chatter feature, Fig.9 demonstrates the comparison of the displacement of the machined workpiece in stable and unstable states. It can be seen that when chatter emerged the amplitude of vibration was increased, and in the spectra, in addition to the spindle rotation frequency $f_{s}=19.5 \mathrm{~Hz}$ caused by deflection or eccentricity of the rotating rod owing to the cutting force, there exists a critical chatter frequency $f_{c}=388.4 \mathrm{~Hz}$ which is a little higher than the natural frequency of the spindle-workpiece-tailstock system (see Fig. 7). Obviously, the rotation frequency appearing at $f_{s}$ related to the forced vibration, persists independently 
during the cutting operation, while the chatter frequency component at $f_{c}$ corresponding to the self-excited vibration depends on the cutting conditions.
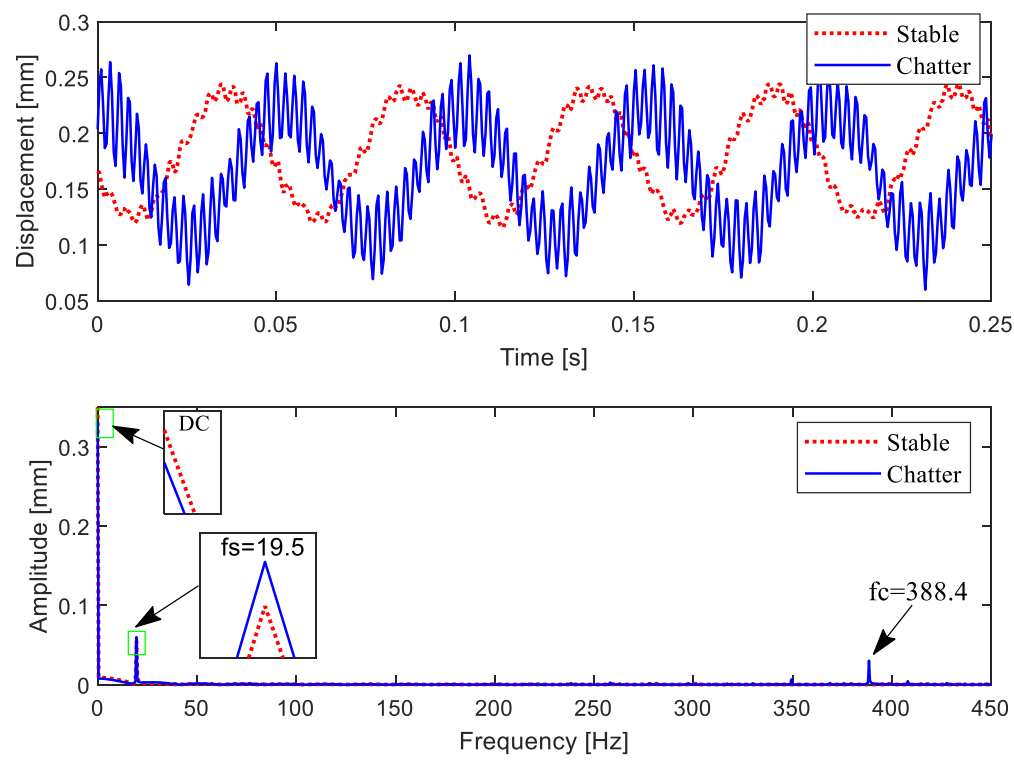

Fig. 9 Comparative features of vibrations in stable and unstable states.

As interpreted above, the changing structural characteristics due to the tool movement could induce variations of the system behavior and hence the level of the process stability. In the chatter onset aspect, four different depths of cut, that is, 0.6, 0.8, 1, $1.2 \mathrm{~mm}$ along with unchanged spindle rotation speed $\Omega=1120 \mathrm{rpm}$ and feedrate $f=0.1 \mathrm{~mm} / \mathrm{rev}$ were employed in the experiments. The experimental and theoretical chatter onset locations along the cutting path are compared in Fig.10, where the cutting coefficient was estimated to be $K_{c}=614 \mathrm{MPa}$ based on the experimental results in [7]. It can be seen that with increase of depth of cut the chatter onset location was likely to approach to the live center end. Comparatively, the finite element model could provide more accurate chatter onset prediction, which further approves that modeling of the spindle and tailstock has a great influence on the dynamic characteristics of flexible workpieces in turning processes. It is worth mentioning that the nonlinear factors in machining operations which are not included in this study, such as the joint stiffness, process damping, and tool wear/crack, could also affect the chatter stability of the machining system $[19,20,32-34]$. 


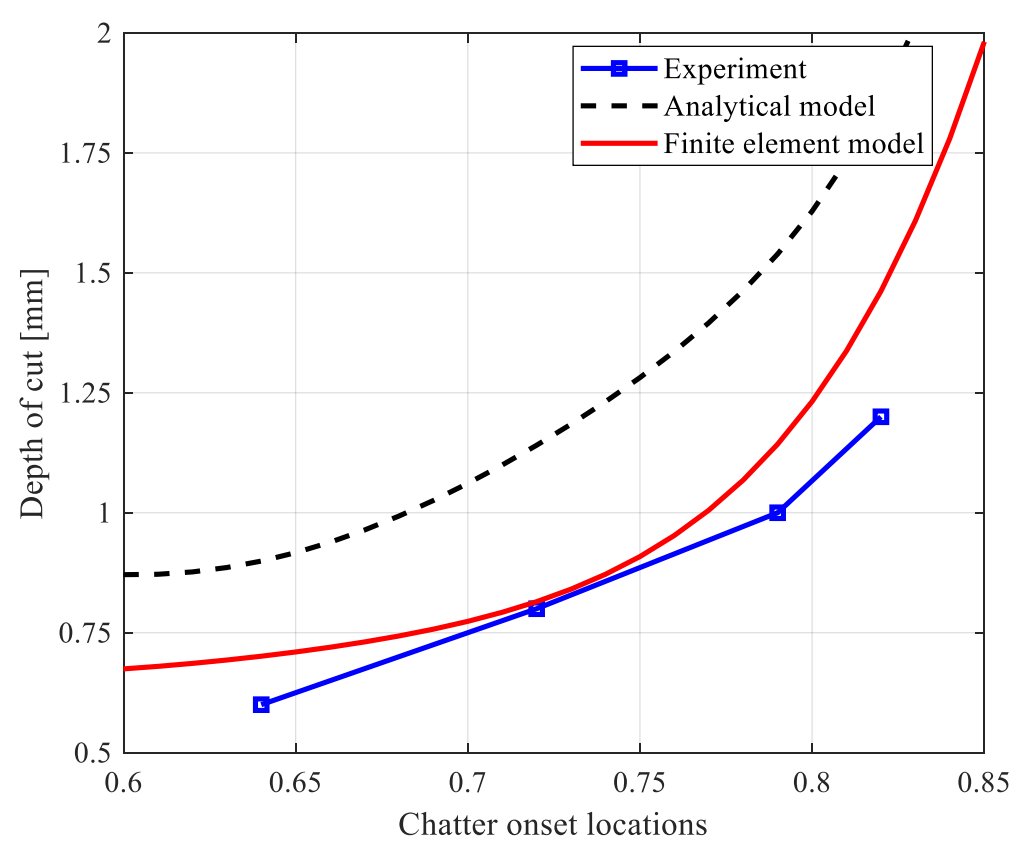

Fig. 10 Comparison of the experimental and predictive chatter onset locations.

\section{Conclusions}

In this paper, the analytical and numerical models of the spindle-workpiece-tailstock system for turning flexible parts were established respectively. Considering the tool movement the chatter stability analysis of the cutting system along the cutting path was formulated. The critical stiffness expression for prediction of chatter onset position was deduced. By comparing with the experimental measurements, it has been proved that the spindle support bearing and chuck play a non-negligible role in dynamic characteristics of the cutting system. The stiffness distribution along the length and the natural frequency of the machined rod cannot be improved effectively by increasing the spindle bearing and center support stiffness. The chuck size has a great effect on the eigenfrequency of the machined workpiece.

Comparatively, the analytical structural model is generally much stiffer than the finite element model or the experimental results. And the model including the effect of bearing and chuck enables to produce more reasonable and accurate chatter onset location prediction. The measured signals showed a good agreement with the theoretical conclusion that the workpiece that is not chattering is still vibrating in turning operations. The displacement sensors could simultaneously capture the useful information of the operation induced by the static and dynamic cutting forces, which can be used for evaluating the shape error of the turned rod and the cutting state at the same time. This could be an advantage to be implemented for machining condition monitoring of the flexible parts. 


\section{Acknowledgments}

The first author is currently an academic visitor at the Center for Efficiency and Performance Engineering (CEPE) of the University of Huddersfield, which has been sponsored by China Scholarship Council. The authors are also grateful for the support of National Natural Science Foundation of China under grant No. 51805352.

\section{References}

1. Altintas Y, Weck M (2004) Chatter stability of metal cutting and grinding. CIRP Ann-Manuf Technol 53(2):619-642

2. Cardi AA, Firpi HA, Bement MT, Liang SY (2008) Workpiece dynamic analysis and prediction during chatter of turning process. Mech Syst Signal Process 22:1481-1494

3. Siddhpura M, Paurobally R (2012) A review of chatter vibration research in turning. Int J Mach Tools Manuf 61:27-47

4. Lu K, Jing M, Zhang X, Dong G, Liu H (2015) An effective optimization algorithm for multipass turning of flexible workpieces. J Intell Manuf 26:831-840

5. Rivin EI 1999Stiffness and Damping in Mechanical Design, Marcel Dekker, New York

6. Tian L, Wu J, Xiong Z, Ding H (2015) Active chatter suppression in turning of low-rigidity workpiece by system matching. In: Proceedings of Intelligent Robotics and Applicatons- $8^{\text {th }}$ International Conference, ICITA 2015: 609-618

7. Urbikain G, Lopez de Lacalle LN, Campa FJ Fernandez A, Elias A (2012) Stability prediction in straight turning of a flexible workpiece by collocation method. Int J Mach Tools Manuf 54-55: $73-81$

8. Chen CK, Tsao YM (2006) A stability analysis of regenerative chatter in turning process without using tailstock. Int J Adv Manuf Technol 29 (7-8):648-654

9. Vela-Martinez L, Jauregui-Correa JC, Rubio-Cerda E, Gilberto HR, Alejandro LG (2008) Analysis of compliance between the cutting tool and the workpiece on the stability of a turning process. Int J Mach Tools Manuf 48(9): 1054-1062

10. Sekar M, Srinivas J, Kotaiah K, Yang S (2009) Stability analysis of turning process with tailstock-supported workpiece. Int J Adv Manuf Technol 43: 862-871

11. Siddhpura M, Siddhpura A, Paurobally R (2017) Chatter stability prediction for a flexible toolworkpiece system in a turning process. Int J Adv Manuf Technol 92:881-896

12. Lu K, Lian Z, Gu F, Jun H (2018) Model-based chatter stability prediction and detection for the turning of a flexible workpiece. Mech Syst Signal Process 100:814-826

13. Wang ZC, Cleghorn WL (2002) Stability analysis of spinning stepped-shaft workpieces in a turning process. J Sound Vib 250(2):356-367

14. Baker JR, Rouch KE (2002) Use of finite element structural models in analyzing machine tool 
chatter. Finite Elem Anal Des 38:1029-1046

15. Mahdavinejad R (2005) Finite element analysis of machine and workpiece instability in turning. Int J Mach Tools Manuf 45:753-760

16. Yu SD, Shah V (2008) Theoretical and experimental studies of chatter in turning for uniform and stepped workpieces. J Vib Acoust 130(6):1005-1018

17. Otto A, Khasawneh FA, Radons G (2015) Position-dependent stability analysis of turning with tool and workpiece compliance. Int J Adv Manuf Technol 79:1453-1463

18. Stepan G, Kiss AK, Ghalamchi B, Sopanen J, Bachrathy D (2017) Chatter avoidance in cutting highly flexible workpieces. CIRP Ann-Manuf Technol 66:377-380

19. Yan Y, Xu J, Wiercigroch M (2019) Modeling of regenerative and frictional cutting dynamics. Int J Mech Sci 156:86-93

20. Deshpande N, Fofana MS (2001) Nonlinear regenerative chatter in turning. Robot Cim-int Manuf 17(1-2): 107-112

21. Lorong P, Larue A, Duarte AP (2011) Dynamic study of thin wall part turning. 13th CIRP International Conference on Modeling of Machining Operations 2011:591-599

22. Zeng S, Wan X, Li W, Yin Z, Xiong Y (2012) A novel approach to fixture design on suppressing machining vibration of flexible workpiece. Int J Mach Tools Manuf 58: 29-43

23. Ritou M, Rabreau C, Loch SL, Furet B, Numur D (2018) Influence of spindle condition on the dynamic behavior. CIRP Ann-Manuf Technol 67(1):419-422

24. Postel M, Özsahin O, Altintas Y (2018) High speed tooltip FRF predictions of arbitrary toolholder combinations based on operational spindle identification. Int J Mach Tools Manuf 129:4860

25. Rao S (2011) Mechanical Vibrations - $5^{\text {th }}$ edition, Pretice Hall, Upper Saddle River

26. Harris T (1984) Rolling Bearing Analysis, John Wiley, New York

27. Landers RG, Min BK, Koren Y (2001) Reconfigurable machine tools. CIRP Ann-Manuf Technol 50(1):269-274

28. Chen Y, Dong F (2013) Robot machining: recent development and future research issues. Int J Adv Manuf Technol 66(9-12):1453-1463

29. Mao K, Li B, Wu J, Shao X (2010) Stiffness influential factors-based dynamic modeling and its parameter identification method of fixed joints in machine tools. Int $\mathrm{J}$ Mach Tools Manuf 50(2):156-164

30. Chang JY, Lai GJ, Chen MF (1994) A study on the chatter characteristics of the thin wall cylindrical workpiece. Int J Mach Tools Manuf 34(4):489-498

31. Mehdi K, Rigal JF, Play D (2002) Dynamic behavior of a thin-walled cylindrical workpiece during the turning process, Part 2: Experimental approach and validation, J Manuf Sci Eng-T ASME 124:569-580

32. Gilsinn D, Davies M, Balachandran B (2001) Stability of precision diamond turning processes 
that use round nosed tools. J Manuf Sci Eng-T ASME 123(4): 747-748

33. Balachandran B, Gilsinn D (2007) Nonlinear oscillations of milling. Math Comp Model Dyn $11: 273-290$

34. Fu C, Ren X, Yang Y, Lu K, Qin W (2019) Steady-state response analysis of cracked rotors with uncertain-but-bounded parameters using a polynomial surrogate method. Commun Nonlinear Sci 68: $240-256$ 